\title{
Market Structure, Liquidity, and Information Based Trading at the Prague Stock Exchange
}

\author{
Libor Němeček, CERGE-EI \\ and \\ Jan Hanousek, CERGE-EI and WDI ${ }^{1}$
}

\begin{abstract}
This paper investigates the relation between liquidity and information based trading and the possible impact of market microstructure changes on this relationship. A model similar in spirit to that of Easley et al. (1996) is used to determine how often new information occurs and how it influences the composition of orders submitted to the market. There have been several major market structure changes implemented by the Prague Stock Exchange (PSE) over the past five years. Thanks to its unique development path, where a given set of stocks were subjected to several changes in trading environment design, PSE trading data can be used to examine how market conditions impact the extent of informed trading and market liquidity.
\end{abstract}

Keywords: market microstructure, liquidity, informed trading, Prague Stock Exchange JEL Classification: G14, G15

\footnotetext{
${ }^{1}$ CERGE-EI, a joint workplace of Charles University and the Academy of Sciences of the Czech Republic, Prague. Corresponding author: Jan Hanousek, CERGE-EI, P.O. Box 882, Politických vězňů 7, 11121 Prague 1, Czech Republic.

E-mail: jan.hanousek@cerge.cuni.cz. Detailed descriptions and additional computations are available at $\underline{\text { http://home.cerge-ei.cz/hanousek/PSE }}$ or upon request.
} 


\section{Introduction}

In the framework of newly emerged Central and Eastern European capital markets, the lack of regulations would negatively affect overall functioning of the market. Investors are usually concerned about transparency, liquidity and market structure, so negative features like significant information/insider trading would erode investor confidence in a given capital market and cause the withdrawal of foreign and local institutional investors. In such circumstances capital markets cannot fulfill their key role - bringing new capital for companies and transferring savings to investment.

Surprisingly, policy makers in several Central and Eastern European countries have ignored these considerations and allowed a non-standard creation of capital markets in their countries (typically as a by-product of voucher privatization programs). ${ }^{2}$ The Czech Republic is an illustrative case, since policy makers ignored the step-by-step creation of the capital markets and simply transferred hundreds of voucher shares to the newly created market. As opposed to the classical gradual way, they transferred vast number of shares without any listing requirement, which created a complicated and non-transparent market environment. Many practitioners argued that this ill-conceived approach would not create a functioning market, and that in combination with the lack of a strong supervisory body there would be enormous latitude for informed/insider trading.

Let us note that estimation of information driven trading covers two components: legal trading and illegal insider trading. In theory there is a dear difference between these

\footnotetext{
${ }^{2}$ See for example reports of European Bank for Reconstruction and development EBRD 1996-2000, as well as early issues.
} 
components; however, in transactions data both informed and insider trading have similar effects and thus it is not feasible to separate the two without more detailed data. ${ }^{3}$

The current paper estimates the extent of informed trading on the Prague Stock Exchange (PSE) over the period 1993-2000, hence covering significant changes in market structure. Let us note that while starting years are associated with the birth of the market and transfers of hundreds of shares from voucher privatization, later we can observe several institutional changes. These changes include introducing different tiers (with different qualification and information-disclosure requirements); de-listing a large number of shares; and changing the secondary market organization from a single price auction market to a continuous price auction market and then a combined auction and dealers' market. Therefore, by estimating the extent of information/insider trading over those periods, we can test the sensitivity of our findings with respect to differences in institutional structures. This approach should enable us to analyze the relative influence of market structure on the extent of informed trading on the PSE. Let us list a few major questions/hypotheses we would like to address:

- One would expect the probability of informed trading to increase with decreasing liquidity (increased probability of non-trading). This hypothesis relates to the higher importance of more liquid stocks both in the information transmission process and weight in agents' portfolios. A closer analysis of these stocks would then leave less space for non-public information based trading to occur.

- For a given stock or group of stocks, one would expect the probability of informed trading to decrease over time. This hypothesis is based on an assumption of increasing

\footnotetext{
${ }^{3}$ Bhattacharya et al. (2000) is one of the very few studies that deals with insider and informed trading on emerging markets.
} 
market efficiency, due both to the gained experience of market players and to changes in market structure aimed at improving market transparency and liquidity.

- Introduction of a large number of new stocks (from the second wave of voucher privatization) should lead to an increase in the average probability of informed trading for all stocks. This would happen when the limited resources of market players to collect and analyze market- and firm-specific information signals get diluted as the total number of listed stocks doubles. However, this effect is supposed to be temporary and the average probability of informed trading is expected to fall afterwards.

The paper is structured as follows. Section two offers a brief description of the PSE, followed with the model of Easley et al. (1996). Section four presents our results. The last section concludes and carries out some policy recommendations. 


\section{The Model}

\subsection{Trading Mechanism of the Prague Stock Exchange (PSE)}

Trading at the PSE is maintained and a price is set by the Automated Trading System (ATS), which clears the buy and sell orders ${ }^{4}$ for each stock. The goal of the clearing procedure is to maximize the number of shares traded. In this setting, where shares trade via order driven auctions, the role of market versus limit orders is quite different than in a continuous trading framework. In the continuous auction, the limit orders waiting in the market makers' limit-order book provide market liquidity and can be matched with the market orders as the latter arrive at the market. However, in the clearing mechanism of the type described above, the market orders are those which by matching any limit order increase the stock's volume of trade and liquidity.

A crucial feature of the PSE's price-setting mechanism is the upper limit on the percentage price change: for most issues, the price can change by at most $5 \%$ during a single trading day (auction). Comparison of demand and supply patterns during the pricesetting process can therefore have several qualitatively different outcomes. These are summarized in the variable called "code of the market," (published by the PSE) which can take one of eight values. Values of this "code of the market" variable, together with values of the allocation ratio variable (which capture the extent of order rationing), can be used to reconstruct the numbers of shares demanded and supplied. We discuss this reconstruction more thoroughly in the next section where the model's structure is presented.

\footnotetext{
${ }^{4}$ The order may have a price limit specified, i.e., a maximum price for a buy and a minimum price for a sell order. If the limit price is not specified, it is a simple market order.
} 
Let us note that the pre-opening phase is an important part of the trading mechanism of the Prague Stock Exchange (PSE). ${ }^{5}$ Other markets also use an instrument of the opening auction to process the trading orders accumulated since the closing of the market on the previous trading day. B. Biais et al. (1999) studies the tatonnement process and tests the noise hypothesis against the hypothesis that the pre-opening prices reflect learning. On the Paris Bourse, traders can place, modify, and cancel various types of orders and instantly observe the resulting indicative prices and trading volume, without any trades actually taking place. This gives them an opportunity to test market sentiment and to send pricing/trading signals to the market, both informative and manipulative, without the associated costs of trading. ${ }^{6}$ And yet, albeit representing a very interesting exercise with important insights, their methodology unfortunately does not apply to the context of the Prague Stock Exchange.

The key difference between the Prague Stock Exchange and the Paris Bourse is that while orders can be submitted, modified and canceled during the pre-opening period on the PSE, no information is released during that period. Traders thus have no feedback on orders submitted by other traders nor on movements in market demand and supply. No

\footnotetext{
${ }^{5}$ In the pre-opening phase, i.e. between 17:00-20:00 on the previous trading day and between 7:30-10:00 on the current trading day, traders can submit orders that are then executed in the opening auction at 11:00 on the trading day. A continuous trading then follows. Because the opening is structured as a uniform-price auction, the market impact of individual orders and adverse selection problems are likely to be less pronounced in the opening auction.

${ }^{6}$ The fact that traders observe changes in market demand and supply is crucial for their ability to infer market information during the pre-opening period and to possibly adjust their trading strategies based on such information. This market setup led Biais et al. (1999) to the formulation of the learning hypothesis and its testing using the GMM method.
} 
learning process can take place during the pre-opening period, nor can the orders submitted be used to influence information sets and price expectations of other traders. We thus argue that during both the pre-opening period and the subsequent continuous trading, the arrival of traders to the market (information arrival and subsequent order submission) can be modeled using an independent Poisson process as used in the Easley et al. (1996) model.

\subsection{The Structural Setup of the Model}

Two observable pieces of information, the degree of demand and supply imbalance measured by the "code of the market" variable and the number of shares demanded and supplied at the new market price, can be used in the model to provide insights into trade and information flows.

Traders arriving at the market can either be uninformed or informed about the stock's value. Each day, prior to the beginning of the period in which traders submit orders, chance determines whether an information event relevant to the value of the particular asset will occur. These information events are assumed to be independently distributed and to occur with probability $\alpha$. There is good news with probability $1-\delta$, and bad news with probability $\delta$. Informed investors know these signals while uninformed ones do not.

As do Easley et al. (1996), we assume that the arrival of uninformed buyers and sellers at the market (i.e., their decision to trade and the actual submission of orders - to be considered in the upcoming auction) is determined by an independent Poisson process with the arrival rate $\varepsilon$. The arrival of signals to the other traders and their subsequent arrival at the market are assumed to follow a Poisson process with the arrival rate $\mu$. Observing a good or bad signal leads to the submission of a buy or sell order. This "informed trading" process is also assumed to be independent of the arrival processes of uninformed traders. 
The cited Poisson processes result from each agent deciding (not having information or observing a signal) whether to trade at the market or not. They do not capture the decision about the type of order (market versus limit) and, in the case of a limit order, the decision about limit price. In fact, we assume that two possibilities as referent is independent of the decision on whether to trade, and we thus model it with the ad hoc construction described below.

If $\mathrm{P}_{\mathrm{t}-1}$ is the previous day price of the stock and $\mathrm{P}_{\mathrm{t}}{ }_{\mathrm{t}}$ is the new price, define the price change $\mathrm{p}^{*}=\left(\mathrm{P}_{\mathrm{t}}^{*}-\mathrm{P}_{\mathrm{t}-1}\right) / \mathrm{P}_{\mathrm{t}-1}$ and measure the price of the stock on a given day by the relative price change $p^{*}$. Because of price change limits due to the PSE's trading mechanism, a trade could never occur at a price outside the admissible (5\%) interval. We can, therefore, think of market orders as a special type of limit order with the limit price set $5 \%$ below or above the previous day price in the case of sell or buy orders. The limit prices of particular orders submitted are distributed discretely at the admissible interval. This is approximated here by a continuous logistic function, which specifies the number of shares demanded at price $\mathrm{p}$ as

$$
B(p)=A^{D} \frac{e^{-\beta p}}{1+e^{-\beta p}},
$$

where $\beta$ is the parameter, and $A^{D}$ is the total number of shares demanded - irrespective of possible limit prices of corresponding buy orders — which was assumed to follow a Poisson distribution.

Similarly, the number of shares supplied at price $\mathrm{p}$ is modeled as

$$
S(p)=A^{S} \frac{e^{\beta p}}{1+e^{\beta p}},
$$


where $A^{S}$ is the total number of shares supplied - irrespective of the corresponding limit prices — which also follows a Poisson distribution.

Depending on the relative position of $B(p)$ and $S(p)$, driven by the realization of $A^{D}$ and $\mathrm{A}^{\mathrm{S}}$, there are three possible outcomes:

a) Demand and supply patterns cross for $\mathrm{p}^{*}$, which lies inside the admissible region. This corresponds to "codes of the market" 1,2 , and 3 in the real data.

b) The new price is at the boundary and the allocation ratio is greater than or equal to $20 \%$. This corresponds to "codes of the market" 4 and 5 in the data.

c) The allocation ratio for $\mathrm{p}^{*}$ at the boundary of the admissible region is lower than $20 \%$, or there are no orders submitted on either the buy side or sell side of the market. This means that no trade is made and corresponds to "codes of the market" 6,7 , and 8 in the real data.

Codes 1,2 , and 3 correspond to the situation in which the market price $\mathrm{p}^{*}$ proposed by the ATS falls inside the admissible interval, and all orders valid at that price are executed. In that case, the number of shares demanded, $\mathrm{B}\left(\mathrm{p}^{*}\right)$, is equal to the number of shares supplied, $\mathrm{S}\left(\mathrm{p}^{*}\right)$. If the new price lies at the boundary (codes 4 and 5), some orders may be rationed. The extent of rationing is given by an allocation ratio published by the PSE. This ratio can therefore be used to reconstruct the quantities $\mathrm{B}\left(\mathrm{p}^{*}\right)$ and $\mathrm{S}\left(\mathrm{p}^{*}\right)$ from the number of shares actually exchanged.

Given the parameter $\beta$, the number of shares demanded and supplied at the new price $p$ can be used to compute the (unobservable) total amounts demanded $\left(\mathrm{A}^{\mathrm{D}}\right)$ and supplied $\left(\mathrm{A}^{\mathrm{S}}\right)$. While it is possible to reconstruct these numbers for cases a) and b) corresponding to the "codes of the market" $1, \ldots, 5$, it is not possible to infer them from the information published in the case of no trade ("codes of the market" 6, 7, and 8). 
There are several ways to deal with this problem. First, one can simply condition on nonzero trade volume and restrict ourselves to the "codes of the market" $1, \ldots, 5$. Or, given the structural setup of the model, it is in principle possible to compute the probability of no trade as a function of structural parameters explicitly from the assumptions on demand and supply patterns and to use the observations with "codes of the market" 6,7 , and 8 to obtain more efficient estimates of the model's parameters. This would, however, involve computing quantiles of the ratio of two Poisson random variables - extremely cumbersome.

This paper uses the first approach and uses trading days with "codes of the market" 1 to 5 only. The structure of the proposed model is illustrated in Figure 1.

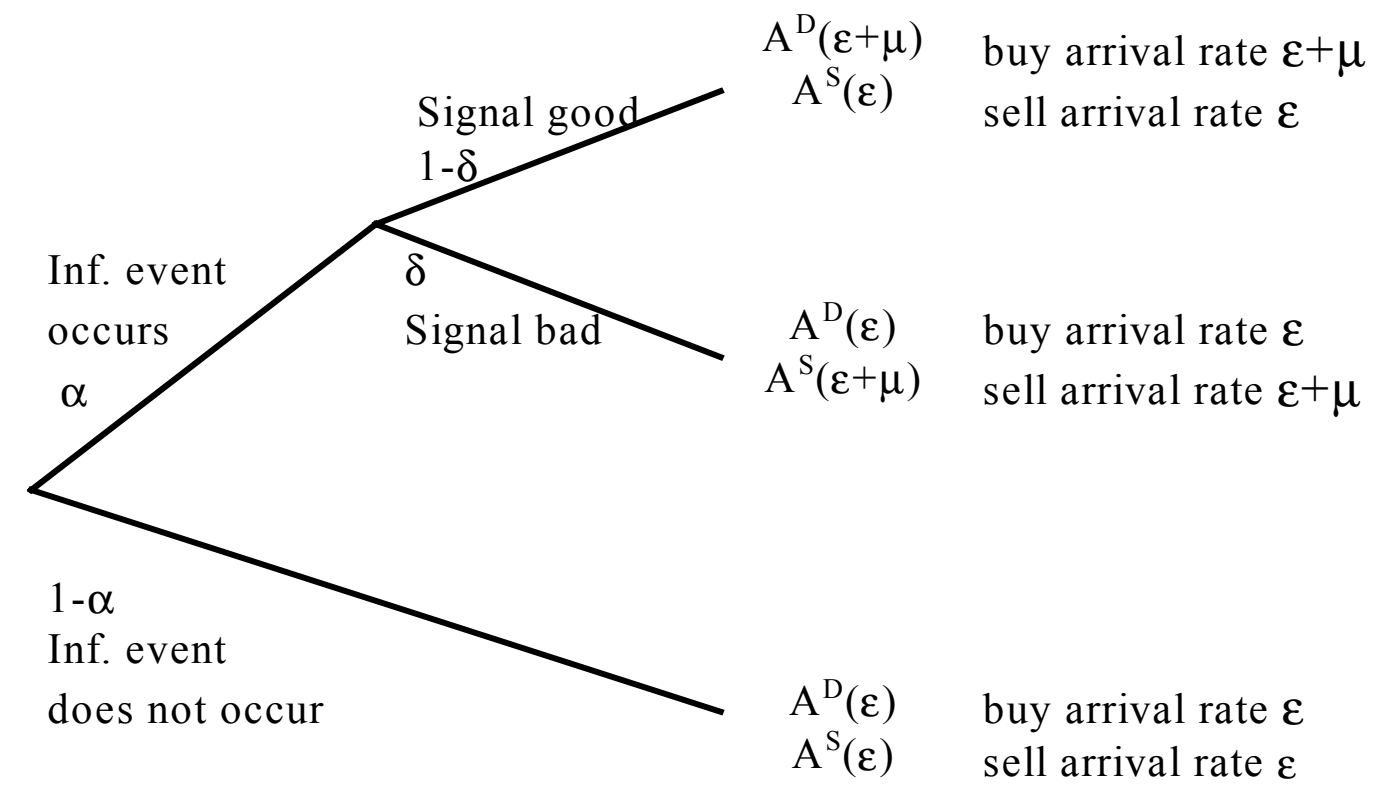

Figure 1: Tree diagram of the trading process. $\alpha$ is the probability of an information event, $\delta$ is the probability of a bad signal, $\varepsilon$ is the arrival rate of uninformed traders, $\mu$ is the arrival rate of informed traders. $\mathrm{A}^{\mathrm{D}}(\omega)\left(\mathrm{A}^{\mathrm{S}}(\omega)\right)$ indicates that the total number of shares demanded (supplied) follows a Poisson process with the arrival rate $\omega$. These values are unobserved if there is no trade. Otherwise they can be reconstructed [using (1) and (2)] from the data on shares demanded and supplied at the new price. 
The parameters to be estimated for a given stock are $\alpha, \delta, \varepsilon, \mu$, and $\beta$. The primary goal of this paper, however, is to estimate the extent of information based trading. Based on the branch of the tree prevailing on a given day, buy and sell orders follow different arrival processes. The "average arrival rate" of informed traders is $\alpha((1-\delta) \mu+\delta \mu)+(1-$ $\alpha)^{*} 0=\alpha \mu$. The "average arrival rate" of all traders is $\alpha((1-\delta)(\mu+2 \varepsilon)+\delta(\mu+2 \varepsilon))+(1-\alpha) * 2 \varepsilon$ $=\alpha \mu+2 \varepsilon$. The overall probability of informed trading is given by the ratio of these two expressions, so

$$
P I=\frac{\alpha \mu}{\alpha \mu+2 \varepsilon}
$$

\section{The Data}

The Czech capital market was created as a by-product of the voucher privatization program. In the aftermath of voucher privatization, basically all equities were put on the newly emerged capital market. This meant that the standard selective approach to listing shares and demanding detailed periodic information disclosures was not used. The result was a lack of transparency and an unmanageable number of equities for the market to handle. The newly established capital market was flooded by close to one thousand equities from the first wave of voucher privatization in 1993. Another set of about seven hundred equities entered the market after the end of the second wave of voucher privatization in March 1995. Market regulation, however, lagged significantly, insider trading, price manipulation, fraud in the investment funds industry, and abuses of minority shareholder rights greatly eroded investor confidence. In recent years, regulation has improved, but 
enforcement continues to be rather weak (See EBRD 1996-2000; World Bank 1999, among others).

The connection between liquidity and information based trading has been studied by several authors (see, for example, Hasbrouck 1988, 1991, and Easley et al, 1996) using data from developed capital markets. The main purpose of those investigations was to explain the observed differences in spreads between active and infrequently traded stocks. Easley et al. (who used a sample of stocks listed on the New York Stock Exchange) found that the probability of information based trading is lower for high volume stocks. We ask whether similar conclusions hold in an emerging market such as that of the Czech Republic, and, more importantly, what effect market structure changes and overall market size is on the extent of information based trading.

The model derived in the previous section is estimated for a sample of stocks traded on the PSE. All data available from the introduction of a given stock on the market ${ }^{7}$ until February 18, 2000 are used. This time period encompasses the three major phases of PSE development:

- Period 1: 04/06/93 - 02/28/95 represents the creation of the market by transferring firms privatized in the first wave of voucher privatization;

- Period 2: 03/01/95 - 09/30/97 depicts a major increase in the size of the market (number of listed stocks) due to the introduction of shares privatized in the second wave of the voucher privatization;

- Period 3: $10 / 01 / 97-02 / 18 / 00$ is characterized by market shrinkage due to the gradual delisting of infrequently traded shares.

\footnotetext{
${ }^{7}$ June 22, 1993 and March 1, 1995 for most of the stocks offered in the first and second waves of voucher privatization, respectively. The vast majority of stocks entered the market on one of those two dates.
} 
These phases are illustrated by the total number of listed shares in Figure 2.

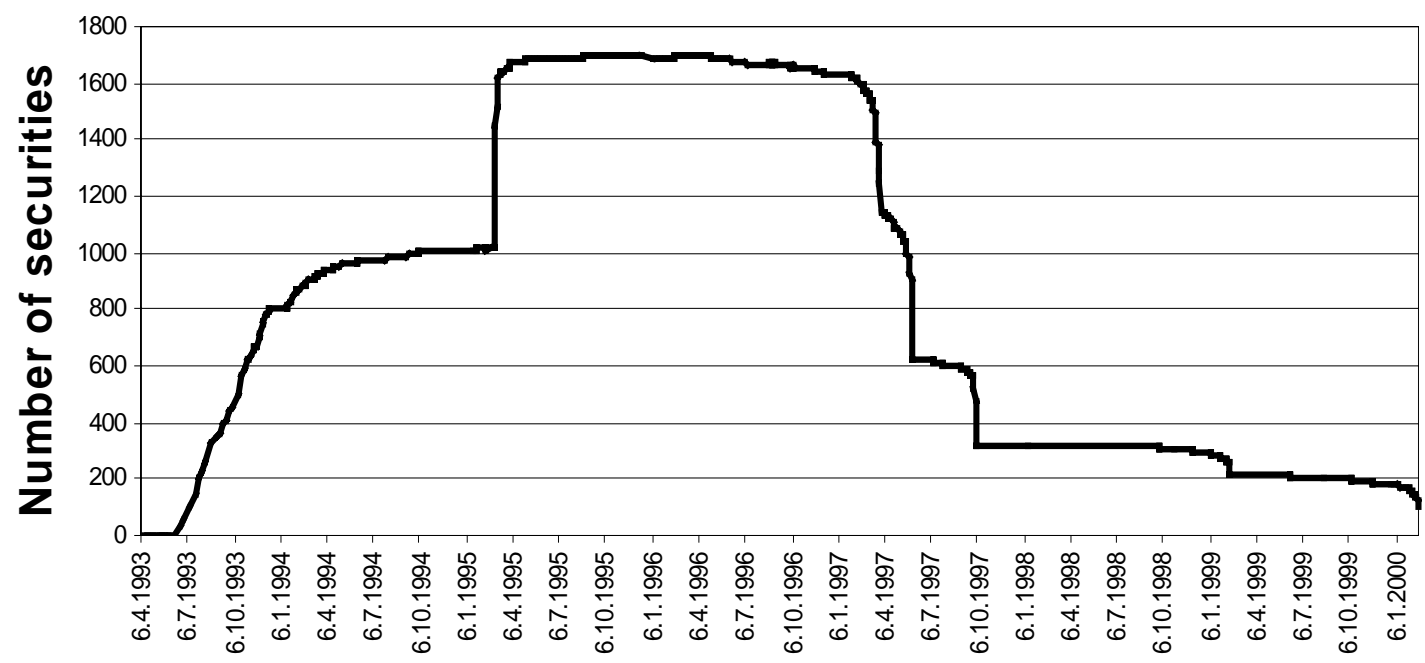

Figure 2: Number of securities listed at the Prague Stock Exchange

As our primary focus is to examine the effects of changes in market size and structure, the model is estimated for a subset of stocks with likely trading probability and traded in a given time period. For each stock in the sample, we need to estimate the parameters of the trading process. These estimates are then compared across groups of stocks and over time periods. Although there were more than 1,750 firms listed on the PSE in 1996, most of them did not trade very frequently during the time period investigated in this paper. Trading frequencies and volumes decrease rapidly as we move from most to least liquid stocks (see Figure 3). 


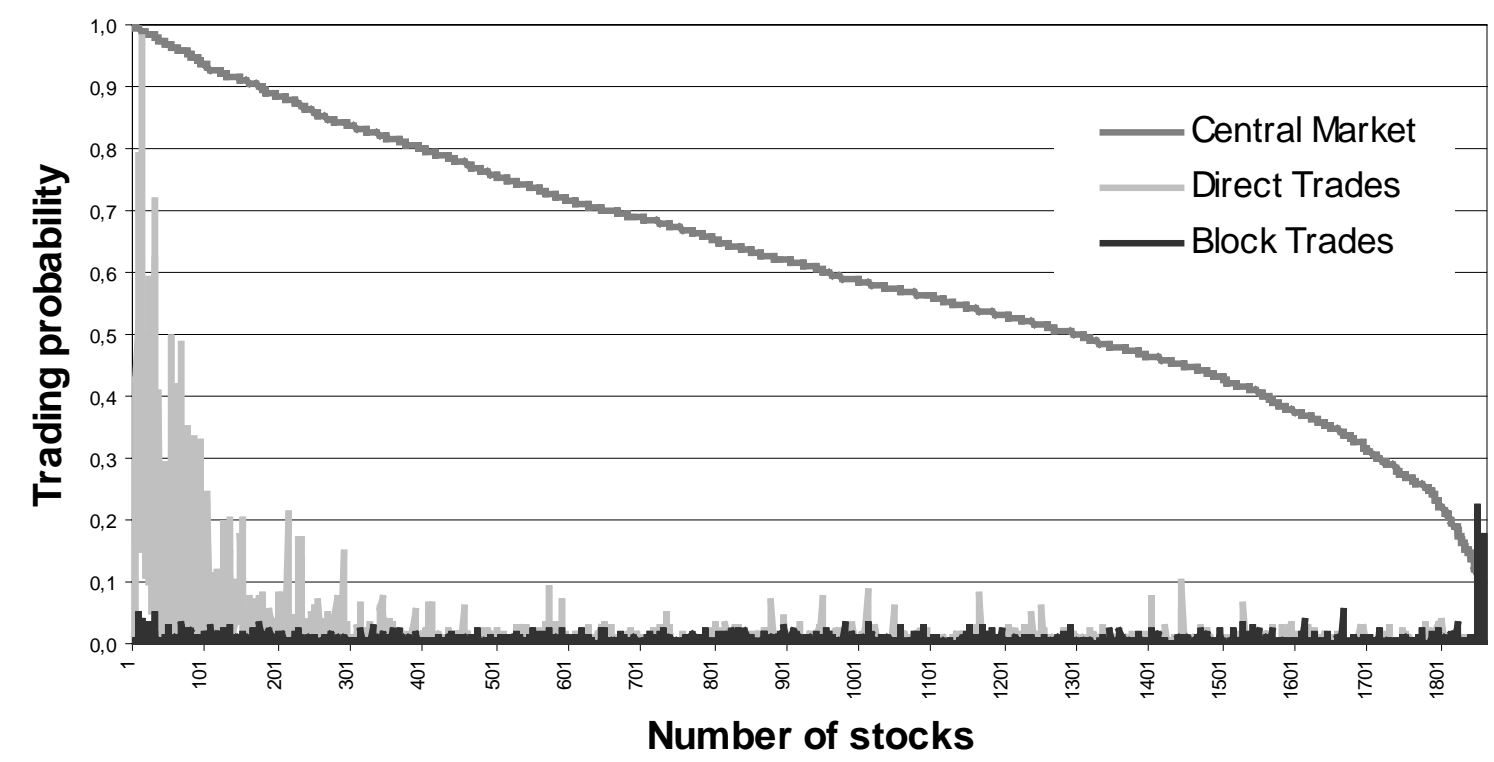

Figure 3: Trading probabilities of securities listed at the Prague Stock Exchange (sorted)

These issues are discussed in detail below, where we describe the sample selection criteria.

First, we investigate the extent of information based trading among stocks traded in all periods defined above. As Period 2 represents the time period with the highest number of shares listed on the PSE, it is taken as a basis for the sample selection in this section. All joint stock companies traded on the PSE during that period were first sorted by average probability of nontrading on a given day. The sample was then divided into deciles, with the first decile containing the most frequently traded stocks.

In all three sub-periods 150 stocks were traded. We also estimate our model for 102 stocks traded only in periods 2 and 3 . As the vast majority of infrequently traded stocks were delisted from the PSE during the third quarter of 1997, the distribution of these stocks is strongly skewed in favor of frequent trading deciles. We also compare the extent of information based trading for groups of stocks defined by probabilities of trading estimated separately in each period. Thus, while we have followed the same groups of stocks over 
time in sections 3.1 and 3.2, the composition of a given nontrading decile used in this section may change from one period to another because of possible changes in the stocks' trading frequency. Within each period, we first sort all stocks according to their trading frequencies. We then assign them to deciles and randomly select 25 stocks from each decile. This procedure yields a sample of 250 stocks in each of the three periods. ${ }^{8}$

\section{Estimation}

We maximized the likelihood function of the model, conditional on trade data for a given stock, to obtain estimates of the trade process and information flow for that stock. ${ }^{9}$ To verify the robustness of different groupings, we have defined three different sampling methods. Results of the model estimation are reported in Table 1 (stocks traded in all periods and only in period 2) and in Table 2 (sampling based on trading probability in a given period).

Surprisingly, we find no clear evidence to validate any of the starting hypotheses listed in the Introduction. There is no clear trend to indicate increasing probability of informed trading with decreasing liquidity. Rather, estimation results suggest that the

\footnotetext{
${ }^{8}$ Descriptive statistics for all criteria, such as their average probabilities of nontrading, average prices, and average market capitalization, are available from the authors upon request.

${ }^{9}$ The probability parameters $\alpha$ and $\delta$ were restricted to $[0,1]$. The arrival rate parameters $\varepsilon$ and $\mu$ were restricted to $(0, \infty)$ by a logarithmic transformation. The re-parameterized likelihood function was then maximized using the ML procedure of the TSP package. Standard errors for the economic parameter estimates were calculated from the asymptotic distribution of the unrestricted parameters using the delta method.
} 
probability of informed trading is highest for stocks with middle-range trading frequencies (third to fifth decile; see Table 3). While we can observe a decrease in average estimated probabilities of informed trading between periods 1 and 2, this probability generally increases between periods 2 and 3. This result is most striking for stocks traded only in the later periods (Table 2).

Table 1: Probability of informed trading. Summary statistics by group for stocks traded in all periods and for stocks traded in the last two periods

\begin{tabular}{|l|ccc|cc|}
\hline & \multicolumn{3}{|c|}{ Traded in all three periods } & \multicolumn{2}{c|}{ Traded in period 2 and 3 } \\
\cline { 2 - 6 } & Period 1 & Period 2 & Period 3 & Period 2 & Period 3 \\
\hline First decile & & & & & \\
Mean & 0.275 & 0.244 & 0.293 & 0.295 & 0.323 \\
Median & 0.009 & 0.329 & 0.349 & 0.351 & 0.331 \\
Std. Dev. & 0.302 & 0.245 & 0.265 & 0.245 & 0.309 \\
\hline Second decile & & & & & \\
Mean & 0.284 & 0.204 & 0.378 & 0.233 & 0.230 \\
Median & 0.227 & 0.000 & 0.417 & 0.257 & 0.072 \\
Std. Dev. & 0.303 & 0.243 & 0.288 & 0.239 & 0.261 \\
\hline Third decile & & & & & \\
Mean & 0.314 & 0.243 & 0.236 & 0.116 & 0.300 \\
Median & 0.361 & 0.134 & 0.147 & 0.000 & 0.383 \\
Std. Dev. & 0.274 & 0.280 & 0.304 & 0.201 & 0.250 \\
\hline $\mathbf{4}^{\text {th }}$-10 decile & & & & & \\
Mean & 0.294 & 0.266 & 0.207 & 0.271 & 0.337 \\
Median & 0.445 & 0.345 & 0.002 & 0.347 & 0.461 \\
Std. Dev. & 0.286 & 0.222 & 0.317 & 0.236 & 0.282 \\
\hline
\end{tabular}


Table 2: Probability of informed trading. Sampling based on trading probability in a given period

\begin{tabular}{|l|ccc|ccc|}
\hline & Period 1 & Period 2 & Period 3 & Period 1 & Period 2 & Period 3 \\
\hline $\mathbf{1}^{\text {st }}$ decile & & & & $\mathbf{6}^{\text {th }}$ decile & & \\
Mean & 0.198 & 0.238 & 0.220 & 0.280 & 0.106 & 0.275 \\
Median & 0.000 & 0.282 & 0.000 & 0.222 & 0.000 & 0.363 \\
Std. Dev. & 0.277 & 0.225 & 0.311 & 0.285 & 0.220 & 0.241 \\
\hline $\mathbf{2}^{\text {nd }}$ decile & & & & $7^{\text {th }}$ decile & & \\
Mean & 0.316 & 0.235 & 0.241 & 0.348 & 0.197 & 0.260 \\
Median & 0.425 & 0.000 & 0.019 & 0.395 & 0.000 & 0.279 \\
Std. Dev. & 0.286 & 0.255 & 0.278 & 0.296 & 0.263 & 0.251 \\
\hline $\mathbf{3}^{\text {rd }}$ decile & & & & $\mathbf{8}^{\text {th }}$ decile & & \\
Mean & 0.324 & 0.321 & 0.426 & 0.261 & 0.176 & 0.293 \\
Median & 0.427 & 0.373 & 0.503 & 0.241 & 0.005 & 0.374 \\
Std. Dev. & 0.251 & 0.308 & 0.288 & 0.236 & 0.265 & 0.246 \\
\hline $\mathbf{4}^{\text {th }}$ decile & & & & $\mathbf{9}^{\text {th }}$ decile & & \\
Mean & 0.343 & 0.163 & 0.319 & 0.145 & 0.254 & 0.273 \\
Median & 0.453 & 0.000 & 0.340 & 0.006 & 0.020 & 0.333 \\
Std. Dev. & 0.267 & 0.252 & 0.299 & 0.209 & 0.295 & 0.285 \\
\hline $\mathbf{5}^{\text {th }}$ decile & & & & $\mathbf{1 0}$ decile & & \\
Mean & 0.263 & 0.141 & 0.393 & 0.312 & 0.285 & 0.238 \\
Median & 0.336 & 0.000 & 0.450 & 0.165 & 0.356 & 0.002 \\
Std. Dev. & 0.256 & 0.248 & 0.282 & 0.360 & 0.277 & 0.304 \\
\hline
\end{tabular}

Thus, the reported estimates of the probability of informed trading and arrival rates across deciles do not clearly support our expectations. Moreover, the variability of the estimates suggests that there are no significant differences in means of the parameters across groups. ${ }^{10}$

Like Easley et al., we compute nonparametric statistics to compare the distributions of estimated variables across groups. Specifically, we used the Kruskal-Wallis test and the Wilcoxon rank sum test. ${ }^{11}$

\footnotetext{
${ }^{10}$ This would fully agree with Easley et al., who also find a similar ranking of different group means on no significance.

${ }^{11}$ The Kruskal-Wallis test serves to check whether the four population distribution functions are identical against the alternative that at least one of them is different. The Wilcoxon test is used for a pairwise
} 
Except for the groups based on trading frequencies estimated separately in each period, where we do find statistically significant differences in probabilities of informed trading among deciles in period 2, we do not observe statistically significant variations in the probability of informed trading (PIT) estimates in any other sample time period. When examining changes over time, however, we do find statistically significant increases in PIT for the first two deciles of stocks traded in all periods and for decile 3 of stocks traded in periods 2 and 3. Using samples defined in section 3.1, we also find significant variations in PIT over time for the $5^{\text {th }}$ to $7^{\text {th }}$ deciles. These results document a significant decrease in PIT in period 2, followed by an increase in PIT in period 3.

\section{Summary of Evidence}

Recent discussions about the connection between liquidity of stocks and the informational role of stock markets yield important insights into market makers' decisions on bid-ask spreads in the framework of continuous-time dealer markets. Empirical studies clearly conclude that low liquidity enhances the risk of information based trading and that wider spreads for infrequently traded stocks do — at least partially — result from market makers insuring themselves against losses from trading with an informed agent. ${ }^{12}$

comparison of these distribution functions and tests whether the values for one sample tend to be higher or lower than for the second sample. Detailed results are available on the web or upon request.

${ }^{12}$ Let us note that the effects of the pre-opening period and opening auction represent an interesting topic. For example, Admati and Pfleiderer (1988) and Pagano (1989) analyze the attractiveness of batching the orders and splitting large orders between the opening auction and the rest of the trading day. Such research goes beyond the scope and goals of the present paper and is also limited by data availability on PSE trading. 
This paper addresses the same problem in the setting of order-driven auction markets. For a sample of PSE stocks, the behavior of active and infrequently traded stocks was investigated. A model, similar in spirit to that of Easley et al. but taking into account the data availability limits and other specifics of the PSE, was proposed and the probability of information based trading was estimated for each stock in the sample. While it was not possible to estimate the underlying demand and supply patterns, the arrival rates of uninformed and informed traders and probabilities of information events were estimated with reasonable precision.

Surprisingly, the results of our model estimation generally do not confirm our $a$ priori expectations but instead reveal insignificant changes or even increases in the probability of informed trading over time. The results also provide little evidence to support the hypothesis that higher liquidity (probability of trading) will translate into lower probability of informed trading.

These observations and trends hinder market regulators from increasing the transparency and liquidity of the Prague Stock Exchange. The results also put in doubt the proclaimed efficiency gains achieved by changes in market structure, e.g. major delistings of less frequently traded stocks. Our results suggest that these changes alone are not sufficient to achieve transparency and efficiency improvements on the Prague Stock Exchange or increase investor confidence in Czech stock markets. 


\section{References}

Admati, Anat R., and Pfleiderer, Paul. "A Theory of Intraday Trading Patterns." Rev. Financial Studies I (Spring 1988): 3-40.

Biais, Bruno, Hillion, Pierre, and Chester Spatt. "Price Discovery and Learning during the Preopening Period in the Paris Bourse." Journal of Political Economy 107(6) (1999): 1218-1248.

Bhattacharya Utpal, Hazem Daouk, Brian Jorgenson, and Carl-Heinrich Kehr. 2000. "When an Event Is Not an Event: The Curious Case of an Emerging Market". Journal of Financial Economics, 55, pages 69-101.

Diamond, D. W. and R. E. Verrecchia. (1991). "Disclosure, Liquidity, and the Cost of Capital," Journal of Finance 46(4): 1325 - 1359.

Easley, D., Kiefer, N. M., O'Hara, M. (1996). “Cream-Skimming or Profit-Sharing? The Curious Role of Purchased Order Flow," Journal of Finance 51(3): 811 - 833.

Easley, D., Kiefer, N. M., O’Hara, M., and J. B. Paperman (1996). “Liquidity, Information, and Infrequently Traded Stocks," Journal of Finance 51: 1405 - 1436.

Hasbrouck, J. (1988). “Trades, Quotes, Inventory, and Information,” Journal of Financial Economics 22: 229 - 252.

Hasbrouck, J. (1991). "Measuring the Information Content of Stock Trades," Journal of Finance 46: 179 - 207.

Pagano, Marco. "Trading Volume and Asset Liquidity." Quarterly Journal of Economics 104 (May 1989): 255-274.

Pagano, M. and A. Röell (1996). "Transparency and Liquidity: A Comparison of Auction and Dealer Markets with Informed Trading," Journal of Finance 51: 579 - 611. 